\title{
FJC Grey Literature: Lady Justice Goes Grey
}

\author{
Lee Lipscomb*, Matt Sarago, Andrew Kaplan
}

Information Services Office, Federal Judicial Center, Washington, 20002, District of Columbia, United States

Copyright $\bigcirc 2017$ by authors, all rights reserved. Authors agree that this article remains permanently open access under the terms of the Creative Commons Attribution License 4.0 International License

\begin{abstract}
The Center recognizes the significant role of the Internet in getting new and lesser-known resources to the legal community because of the ease of accessibility and locating grey literature to answer legal questions. Therefore, the Center developed its new website to function as an open access repository of its robust grey legal collection. Successes and setbacks are revealed as analytics demonstrate an increase and eventual plateau in electronic resource requests. Center information professionals must overcome access issues through improved architecture and search design to maintain current patrons and attract new users to the website. The Center's contribution to the body of grey literature after more than four decades of existence is astounding, but without effective promotion of our collection on the Internet, the rest of the world will never know about this significant body of work.
\end{abstract}

Keywords Grey Literature, US Federal Judiciary, Digital Repository, Internet

\section{Introduction}

The Federal Judicial Center (Center) is the repository for educational materials and research for and about the federal judiciary and courts. The Center has an immense collection of grey literature and is organizing outreach to promote the discovery and use of its many treasures. From selected speeches of Supreme Court justices to the documents chronicling implementation of the Civil Justice Reform Act, the Center has maintained historically vital records to further research on the United States federal judiciary.

The Center's collection is original and has gone beyond the walls of the agency to enhance collections at the University of Pennsylvania's National Bankruptcy Archives, University of Michigan's Inter-University Consortium for Political and Social Research, and the University of California at Los Angeles Social Science Data Archive. The Bureau of National Affairs, National Academies Press, and Westlaw all publish Center resources. Scholars have translated Center resources into 18 languages.

Outreach occurs primarily to the Center's website, www.fjc.gov (currently undergoing a new release) and the US Courts YouTube channel. The Center has experienced successes and promoting materials to lawyers, law professors, and social science researchers. This paper discusses the types of questions the Center's materials answered over the years for these user groups.

The Center recognizes the significant role of the Internet in getting new and lesser-known resources to the legal community because of the ease of accessibility and locating grey literature to answer legal questions. The Center's contribution to the body of grey literature after more than four decades of existence is astounding, but without effective promotion of our collection on the Internet, the rest of the world will never know about this significant body of work.

\section{Literature Review}

Grey literature generally includes non-commercial publications created by academia, business, government, and industry in digital or hard copy forms [1]. However, grey legal literature is not recognized though frequently used and therefore is not firmly established within the genre [2]. Grey legal literature is so on the cusp of grey literature studies that no articles devoted to the topic existed prior to Rucinski and the term was only first used in 1992[2].

Due to the lack of available literature on the topic of grey legal literature, the scope of review was enlarged to include Internet and web based treatment of grey literature as a whole. One of the first experiments of this type was the WebLib approach adopted by the CERN Library in Geneva, Switzerland [3]. The library holdings include resources on particle physics and not law. However, the use of a system allowing content creators to submit and categorize their content directly accelerated the volume and timespan for information input and the accuracy of subject categorization. The STEM community embraced the concept of grey literature, open access, and digital repositories. The legal community resists these innovations for greater access further contributing to a lack of research on grey legal repositories and access [4].

Scope of review also included repositories for access of Electronic Law Journals and databases to uncover information about any non-commercial electronic databases. 
There were minor references to repositories hosted by author affiliated institutions to provide access to their unpublished works [4]. The evolution of electronic prints of legal began with Jurist, a portal hosted by Pittsburgh University, Canada. The Legal Electronic Documents Archive (LEDA), developed by Harvard and Cornell, followed. Finally, the Legal Scholarship network was established.

The document portal model acted as a genesis to more sophisticated databases such as the Australasian Legal Information Institute (AUSTLII) and the Global Legal Information Network (GLIN) [4]. These databases required more robust classification and subject indexing based on their volume of content as international collections of grey legal information.

Despite advancement in the development of legal grey repositories, the legal community could never match the scientific community's level of advancement. Unger [5] supposes that the issue is based on the stringency of legal procedures that restrict technological improvement. Though innovation in grey legal repositories continued in the international realm, the Social Science Information Gateway (SOSIG) Law Gateway project focused on using the Internet and vigorous searches for improved access [6]. The focus on browse and search features of the gateway mimic electronically the workings of a print library, more closely approaching the level of access provided by print content, than any prior repository. The "dual access" method is adopted by Center developers in FJC Online.

Faculty publishing in academia most closely models the output of the Research and History divisions at the Federal Judicial Center. Novak and Pardo [7] recommend the use of enhanced bibliographies, searchable databases, and digital repositories in conjunction on a single website to create multiple points of access for publications of this type. Blume [8] warns information professionals that conservatism and traditionalism among the legal community work against such development and only systems that are considerably superior will overcome community affinity for technical and economic austerity. Lemmer [9] endorses the use project management and change management strategic skills to overcome resistance.

\section{Objectives}

Research objectives are to (1) measure the effectiveness of the Center as a repository of grey legal literature, (2) measure the effectiveness of the Center's policy of promoting digital content through its Internet site, and (3) measure the effect on print distribution by the Center's policy of promoting digital content through its Internet site. These three measures will determine the effectiveness of the Center as a present and future repository for education and research materials for and about the federal judiciary and the courts.

\section{Methods}

Accessing the analytic site for www.fjc.gov provides the total number of digital item downloads annually from 2012 to present. The site provides total counts for Complete Downloads and 206 Hits. Since the focus on dissemination of grey literature, only complete downloads are included [13].

Accessing the statistics section of the FJC Resource Orders Database provides the total count of physical items distributed by mail through the Information Services Office of the Center. Physical items include all Center print and media, video and audio, formats.

These figures were recorded in spreadsheets and charted to view trends over time. Figures prior to 2012 were unavailable from the www.fjc.gov analytics page [13]. Only complete calendar years were included. Therefore, figures were recorded from 2012 to 2015 calendar years only.

\section{Results}

These figures were recorded in spreadsheets and charted to view trends over time. Figures recorded were from 2012 to 2015 calendar years (Table 1) [13].

Table 1. Specific data of FJC.gov downloads and Media \& Publication Orders by Year

\begin{tabular}{|c|c|c|}
\hline Year & Downloads & Orders \\
\hline 2012 & 849,065 & 33,506 \\
\hline 2013 & $1,086,301$ & 32,411 \\
\hline 2014 & $1,468,371$ & 23,254 \\
\hline 2015 & $1,188,892$ & 19,020 \\
\hline
\end{tabular}

Orders are trending downward through 2015 (Figure 1) while downloads from www.fjc.gov are trending upward through 2014 (Figure 2) [13].

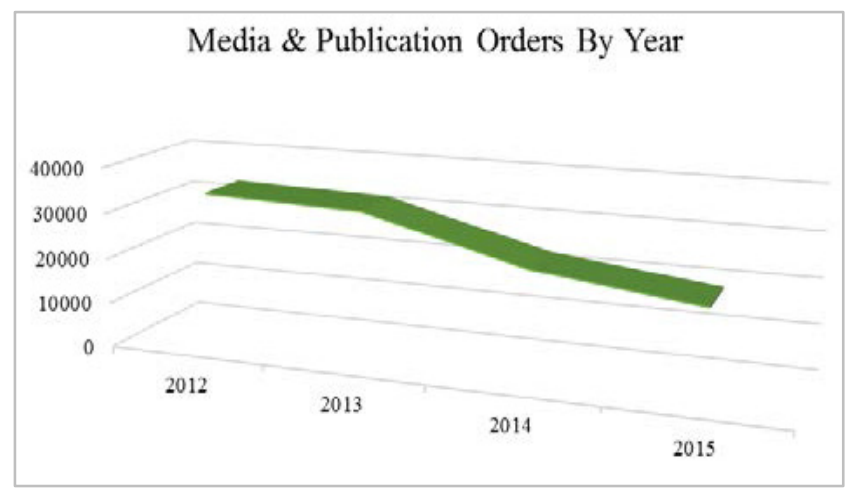

Figure 1. Media \& Publication Orders by Year 


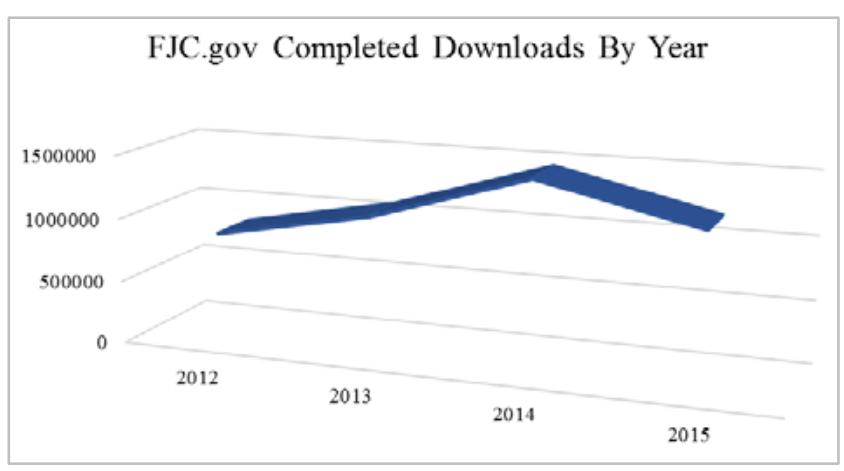

Figure 2. FJC.gov Completed Downloads By Year

This demonstrates that pushing content towards the FJC website as a grey literature repository results in more access to content overall through the website. There is also a diminishing effect on requests for physical copies.

The difference in the level of access between digital and physical is quite significant. In 2012, digital outpaced physical 25 times the latter, in 2013 by 33 times, and in 2014 by 63 times (Table 1, Figure 3)[13].

However, in 2015, digital outpaced physical 62 times, latter indicating that the gains of the digital format stalled (Table 1, Figure 3). This is an interesting finding: identifying its cause is central to the discussion of the effectiveness of web-based tools.

In 2011, 37,814 orders were processed and though no data for comparison is available regarding www.fjc.gov downloads standing alone, this number remains useful as it speaks to the consistent emigration of requests for hard copy sources [13].

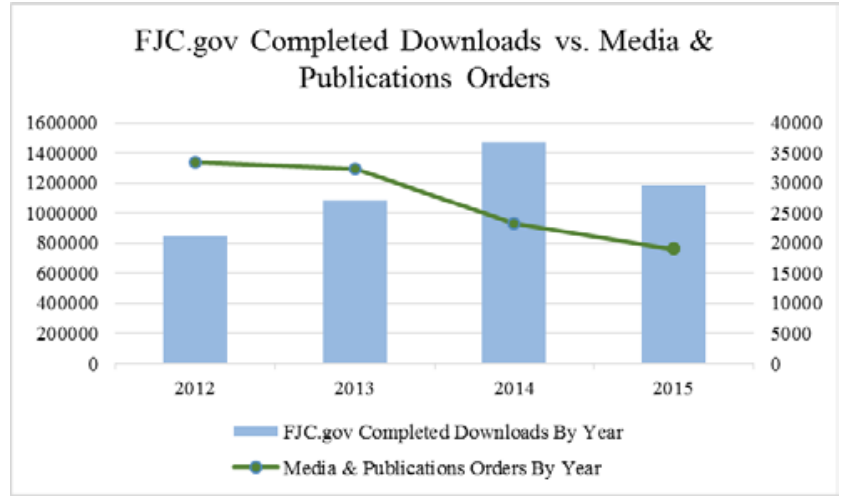

Figure 3. FJC.gov Completed Downloads vs. Media \& Publications Orders

\section{Discussion}

\subsection{Grey Legal Literature Defined}

Grey literature is defined as literature "which is produced on all levels of government, academics, business, and industry in print and electronic formats, but which is not controlled by commercial publishers" [9].
Grey literature production comes through entities centered on knowledge sharing, not profit. The focus is on the quality of information and goal of enriching human experience by providing knowledge to foster community building, education, empowerment, instruction, policy development, and retrospection. Therefore, expensive tools such as distribution chains, advertising campaigns, and marketing strategies are not feasible. Thus, the audiences seeking the types of sources in the Center's collections do not know of its existence or its contents.

Professor Rucinski [2] gives a most comprehensive description of the amalgam that is grey literature:

"[T]ypical examples of grey information resources include "corporate documents, discussion papers, in-house journals and newsletters, surveys, working papers, technical reports, trade association publications, institutional or association reports and bulletins [as well as]... conference proceedings, academic and government reports." Others have included in the grey literature category "unpublished manuscripts... product catalogs... presentations, personal communications... pre-prints, academic courseware, lecture notes, and so on." More recent investigations have proposed pushing boundaries even further to reflect the changing electronic landscape by adding "websites of universities, major libraries, government agencies, nongovernmental organizations including non-profit research organizations, think-tanks and foundations, professional societies, corporations and advocacy groups... [and] documents produced by local governments," not to mention maps, datasets, blog posts, tweets, and social media updates."

The Federal Judicial Center's materials fall within several categories contained within her description.

Within the amalgam lies the niche genre of grey legal literature, "Grey legal literature stands for manifold document types produced on all levels of government, academics, business and industry in print and electronic formats, which inform or are produced by entities affiliated with the law, as part of, or in furtherance of the legislative, executive, and/or judicial administration of the law at the international, federal, state, and/or local level. Grey legal literature is not typically indexed or abstracted but is of sufficient quality to be collected and preserved by government agencies, law libraries, or other interested organizations, but is not controlled by commercial publishers, i.e., where publishing is not the primary activity of the producing body." [10].

Grey literature is amorphous. Its only persistent quality is its non- commerciality. Frequently informal in nature, but not always, grey literature is not defined by its recency or antiquity.

Grey literature is emblematic of the phrase, "The cheek grown thin, the brown hair sprent with grey"[14]. It is often a new and innovative masterpiece compiled for a particular purpose and then cast aside. In due course, the once novel composition's enduring value emerges again years or perhaps decades later. Miraculously, an information seeker 
uncovers the piece recognizing its intrinsic value or a practitioner in the subject matter at hand discovers the work and is immediately aware of its tangible value and sound applicability to their present dilemma. No longer fresh and vibrant, but still as delightful for its perpetual materiality.

In the scope of grey legal literature, the vision of a seasoned Lady Justice with gray locks flowing from beneath her blindfold emerges. The FJC represents her mind, containing her knowledge, reasoning, and memory.

\subsection{FJC \& Grey Legal Literature}

To comprehend the scope and magnitude of this body of work an introduction to the Center and an overview of its purpose is in order. The Federal Judicial Center is the research and education agency of the federal judicial system. Congress established the Center in 1967 (28 U.S.C $\$ \S 620-$ 629 ), on the recommendation of the judicial conference of United States, to "further the development and adoption of improved judicial administration in the courts of the United States." The statutory duties of the Center and its board fall into a few broad categories:

- $\quad$ conducting and promoting research on federal judicial procedures and court operations

- $\quad$ conducting and promoting orientation and continuing education and training for federal judges, court employees, federal defenders, and probation officers

- conducting and fostering the study and preservation of federal judicial history

- providing information and advice to further improvement in the administration of justice in foreign countries and informing the federal judicial personnel of developments in court systems that could affect their work [11]

\subsubsection{Scope of Center Grey Literature}

The most original feature of the Center's purpose is the research mandate. The Center's research division performs research according to requests from the various judicial conference committee and chief judges of the 13 circuits [11]. These pursuits have resulted in hundreds of published reports and manuscripts in digital and print formats [15].

The most expansive feature of the Center's purpose is its education mandate. The Center's education division devises educational programs for all court employees and staff in all US federal jurisdictions [11]. This mandate results in thousands of programs conducted either in person or streamed in large conference or small group settings [15].

The most classic feature of the Center's purpose is its mandate to preserve federal judicial history [11]. The Center's History Division produces collections of judicial history and civics tutorials accessible to the courts and public [15]. This conservancy of court annals has resulted in hundreds of historical writings and curriculum in electronic and print format.
The most global feature of the Center's purpose is its mandate to inform and advise regarding the administration of justice in foreign countries and of foreign countries to the US courts [11]. The Center's International Judicial Relations (IJR) Division conducts foreign delegation visits and produces manuscripts, translations, and legal analysis through its staff and visiting judicial fellows. This mandate has resulted in hundreds of monographs, reports, and chronicles [15].

\subsubsection{Examples of Center Grey Literature}

The contents are rich with primary source material on the courts for legal researchers. These sources fall into three categories: archival, current, and reference. Each category is replete with examples of useful information, useful to a specific legal audience.

Examples of archival materials at the Center are:

- Civil Justice Reform Act collection

- Publications (Deskbook For Sentencing)

- Legislative histories regarding judiciary legislation

- Justices' and Judges' speeches

- Complete chronology of Judicial Conference materials [15]

These appeal to law professors, legal researchers, federal judges, law clerks, and foreign judges.

Current material examples include

- Research and IJR publications (Case Studies in Emergency Election Litigation)

- Educational videos (Supreme Court: Term in review) [15]

Examples of reference materials include

- Databases (Biographical Directory of Federal Judges, 1789-present)

- Educational program documents

- Statistical datasets [15]

\subsubsection{Underrepresentation of Center Literature}

The materials contained in these three categories (archival, current, reference) remain hidden from all but the most relentless of researchers because of a reserved presence on the Internet and in print. The Government Publishing Office (GPO) exclusively prepares FJC print materials, and the GPO bookstore offers no FJC publications [16]. All distribution of print materials occurs through the Information Services Office of the FJC [15].

The outputs of these Center divisions (education, research, history, and international) lead to a body of work underrepresented to the federal judiciary and the public. This underrepresentation is a threefold issue. First, the lack of visibility of the Center as a judiciary information resource. Second, the limited amount of the Center's work available outside the Center. Third, the limited success of mechanisms designed to provide access to Center materials. To counteract the underrepresentation these issues must be resolved through overcoming them as obstacles to achieving the objectives listed above. 


\subsection{Obstacles to Achieving Objectives}

\subsubsection{Effectiveness as a Legal Grey Repository}

The first objective of this research is to measure the effectiveness of the Center as a repository of grey legal literature. The findings of this study indicate that the FJC is successfully providing grey legal literature via the Internet, having reached an apex of 1,468,371 in 2014 (Table 1) [13].

However, post 2014 downloads have leveled off, while print orders decline continues to flatten (Figure 4).

\section{FJC.gov Completed Downloads vs. Media \&} Publications Orders

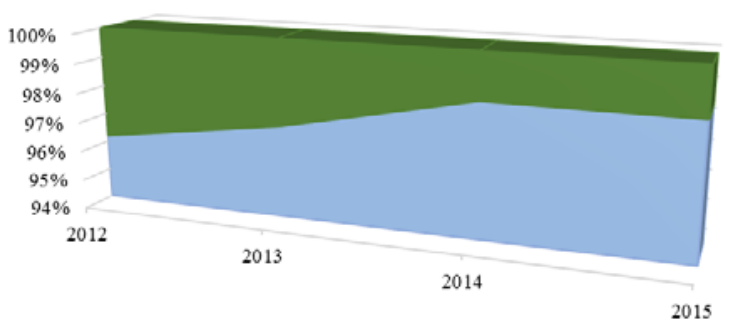

mFJC.gov Completed Downloads By Year $\square$ Media \& Publications Orders By Year

Figure 4. FJC.gov Completed Downloads vs. Media \& Publications Orders Expressed as a \% of Total Distribution

Several obstacles to access have likely led to the leveling off of downloads.

- $\quad$ Lack of visibility

- Lack of findability

- Need for updates to the www.fjc.gov site

- Limited access points to FJC content

- $\quad$ Need for improvements in www.fjc.gov search design

- Need for improvements in www.fjc.gov content management

The first obstacle, lack of visibility, is common to all grey literature repositories. Grey legal literature faces a higher hurdle because of the lack of focus of the grey literature community on this type of grey literature. "Since grey literature has historically fallen under the purview of the sciences, the legal field has understandably struggled to develop a relationship with it. While explicit references to grey literature in the law are few and far between. ..." [2]. Extensive self-promotion and network creation on the part of grey literature authors are the only available vehicles to counteract limited visibility of their publications.

The lack of findability of materials through mainstream Internet channels is another obstruction. Grey literature ranks low in most of the common search engines (e.g. Bing, Google, Yahoo) except when there is little published on a searched topic [2]. Realizing and maintaining high rankings in search results is a highly technical venture that typically requires the assistance of information technology specialists. Therefore, it is cost prohibitive for most grey authors and publishers. The typical findability issues are exacerbated in the case of the FJC because the design of the current www.fjc.gov does not permit search engines to retrieve its records. Because FJC site content is contained in frames the architecture of its current system does not permit access by existing search engines [6].

The need for updates to the present-day Internet site is another impediment. Updates are necessary to bring www.fjc.gov in conformity with modern web standards. The last major update to the site occurred in the ' $90 \mathrm{~s}$. A recent update of the Intranet site will be subsequently pushed out externally to update the Internet site. Upon completion, this project will hopefully increase the repository's benefit to users.

The hurdle of limited access points for Center content also contributes to the flattening of downloads [7]. The Center's website at www.fjc.gov or the US Courts channel on YouTube are the only digital publishing outlets for FJC materials $[13,17]$. The FJC will need to affiliate with other grey Internet repositories or legal entities with a strong web presence to add entry points.

The need for improvements in www.fjc.gov's search design is an obstruction to its practicality as a legal grey repository. Though the current site's search mechanism is successful with simple searches where the user has detailed information regarding the target resource, a user without accurate information or needing to perform a more complex search can experience difficulty in locating items. A more robust and accurate search engine must be part of a new site [6].

The need for improvements in www.fjc.gov content management is the final obstacle for discussion in relation to the effectiveness of the site as a repository. Though there are other functions of the Center's site, its primary purpose is to serve as an access point for FJC content. The organization must work to provide well-organized records replete with full-bodied metadata within a sound structure in its next version of the site [7]. The site must be built with a focus on information architecture and system structure to attain the requisite balance of precision and flexibility to foster successful record retrieval.

Until these issues are addressed and changes are implemented, the number of downloads will likely remain flat. Only users currently experiencing success in maneuvering the system are likely to continue use. In its current state the site will not likely attract new users and will continue to discourage present users with prior disappointing experiences.

\subsubsection{Effectiveness of Digital Content Policy}

FJC's administration decided in 2012 to develop a policy to promote digital content. Three basic tenets construct the policy (1) Publish in digital and print formats (2) Publish digital only whenever feasible (3) Reduce quantities on all print orders. The results over the past three years indicate that the Center's policy of promoting digital content primarily through its Internet site effectually achieves its goal (Table 4). Presently, about $98 \%$ of all FJC content 
distribution flows through www.fjc.gov [13]. This success led the Center to budget savings in print and media cost outlays. This is the only area for savings in physical distribution as all Center materials are provided at no cost since the FJC is a government entity that may not charge for goods or services provided to the courts or the public.

There has been an overall increase in the distribution of Center materials through the website with each year analyzed showing 800,000 to $1,000,000$ additional items distributed digitally than physically (Figure 3) [13].

\subsubsection{Effect on Print \& Media Distribution}

The results show the drastic effect on print and media distribution by the Center's policy of promoting digital content through its Internet site. Physical media and print items delivery reductions ranged between 1,100 and 9,100 approximately per year from 2012 to 2015 (Table 1) [13]. However, after a sharp drop in 2014 dissemination stabilized marginally (Figure 1) [13].

This stabilization could be due to ordering issues as the new Intranet site experiences growing pains or realization of the floor of print and media dissemination. There are patrons and site users that still want materials in print because of personal preference, situational needs, or practicality of use. These reductions are a testament to the Center's success in implementing and executing the new digital content policy.

\section{Conclusions}

Grey legal literature is carving out a niche in the larger grey literature community. The Federal Judicial Center as a high-volume producer of content in this small niche continuously works to establish its place as the foremost source for federal judicial administration, court education, and research resources.

Though the Center faces many of the same obstacles as others maintaining repositories in the grey literature community, it has experienced notable success in its digital content policy execution. Identifying the hindrances to greater efficiencies and volume in providing grey legal literature is the first step in the initiative to launch a new Internet site with greater capabilities and more powerful tools to provide users the legal information they seek.

Ever developing and enhancing its collection of self-authored, published, and distributed materials the Education, Research, History, and International Judicial Relations divisions of the Center remain diligently engaged in producing original information. Using the Internet as its vehicle, the Federal Judicial Center will continue to raise awareness of its significant body of work.

\section{Acknowledgements}

We are very grateful to the FJC's administration for permission to publish this article and the patrons of the
Information Services Office that support our work. We also thank Grey Net and Text Release for sponsoring the International Grey Literature Conference Series that feature our work.

\section{REFERENCES}

[1] J. Schöpfel, D. Farace. Grey Literature, M. Bates and M. Maack eds., Encyclopedia of Library and Information Sciences, 3d ed., note 50, 5, 2011.

[2] T. L. Rucinski. The Elephant in the Room: Toward a Definition of Grey Legal Literature, Law Library Journal, Vol. 107, No. 4, 543-559, 2015-2016.

[3] C. Pettenati. Integration of Grey Literature with Electronic Journals, International Journal of Legal Information, Vol. 30, No. 2, 331-336, 2002.

[4] C. Christiansen. Electronic Law Journals, International Journal of Legal Information, Vol. 30, No. 2, 337-353, 2002.

[5] W. Unger, Development and Present Level of Documentation of Legal Informatics in Europe, International Journal of Law Libraries, Vol. 4, 120-133, 1976.

[6] S. Whittle. Finding Law in the 21st Century: An Introduction to the SOSIG Law Gateway, International Journal of Legal Information, Vol. 29, No. 2, 360-382, 2001.

[7] J. Novak, L. Pardo, The Evolving Nature of Faculty Publications, Legal Reference Services Quarterly, Vol. 26, 209-232, 2007.

[8] P. Blume, Data Retrieval and the Legal System, Yearbook of Law Computers and Technology, Vol. 2, 64-79, 1986.

[9] C. Lemmer, The International Information Consultant: A Primer on Avoiding Potholes, Perils, and Pitfalls, International Journal of Legal Information, Vol. 42, No. 2, 220-240, 2014.

[10] The New York Academy of Medicine. (2016, October 11). What is Grey Literature? Retrieved October 12, 2016, from Grey Literature Report, http://www.greylit.org/about

[11] C. Marzi, G. Pardelli, M. Sassi. A Terminology Based Re-Definition of Grey Literature, Grey Journal Vol. 7, No. 1, 19-20, 2011.

[12] Office of the Law Revision Counsel House. United States Code (2012), Vol. 21, United States Government Printing Office, 296.

[13] Online Available: http://hbwebmetrics.jdc.ao.den/awstats/awstats.pl?month=10 \&year $=2012$ \&output $=$ main \& config $=$ www.f jc.gov\&framename $=$ index

[14] M. Arnold, Thyrsis. Macmillan's Magazine, April, 1866.

[15] Online Available: http://www.fjc.gov

[16] Online Available: https://bookstore.gpo.gov/catalog

[17] Online Available: https://www.youtube.com/user/uscourts 